\title{
Study on the Exercise and Nutrition Intervention on Body Composition and Fitness of Female College Students with Invisible Obesity
}

\author{
Zhang Wei-wei ${ }^{1}$, Yu Ling ${ }^{1 *}$ \\ ${ }^{1}$ Dept.P.E. of Central South University, Changsha, 410083, Hunan, China
}

\begin{abstract}
To observe the effect of exercise intervention and nutrition health education on body composition and fitness of female college students with invisible obesity. 60 female college students with invisible obesity were randomly divided into three groups: control group, exercise intervention group and exercise + nutrition health education group. The control group had normal study and life; the exercise intervention group used aerobic exercise and resistance exercise to carry out collective exercise prescription exercise and individual contract exercise; the exercise intervention + nutrition health education group carried out nutrition health education on the basis of exercise intervention. Before the experiment, the three groups of female college students were homogenous ( $\mathrm{P}>0.05)$; after 16 weeks of the experiment, the body composition and fitness of the exercise intervention group and the exercise intervention + nutrition and health education group were significantly higher than that before the experiment, among which there were significant differences in BMI, $\mathrm{BF} \%$, VFI, vital capacity, $800 \mathrm{~m}$, sit forward flexion and sit up indexes $(\mathrm{P}<0.05)$; after 8 weeks of training, the exercise intervention group was significantly higher than that before the experiment $(\mathrm{P}<0.05)$ The BMI, $\mathrm{BF} \%$ and VFI of the exercise intervention + nutrition health education group continued to decrease $(\mathrm{P}<0.05)$. The combination of aerobic exercise and resistance exercise can reduce the body composition and improve the fitness level of female college students with recessive obesity. The effect of combined intervention of nutrition and health education on the basis of exercise intervention is better than that of single exercise intervention, and it can promote students to form the concept of reasonable nutrition and exercise actively. It is suggested that the correct nutrition concept and active exercise of the recessive obese college students can reduce the body composition and improve the fitness level of the recessive obese female college students.
\end{abstract}

\section{Introduction}

With the rapid development of economy and the technology, people's diet and life in our country has changed a lot, for example, increased energy intake, unhealthy diet, sedentary lifestyle, and decreased physical activity. The rising rates of chronic noncommunicable diseases (such as obesity and high blood pressure) that are related to these changes, has become a severe threat to national health.

According to The National Health Report of 2012, ${ }^{[1]}$ The Nutrition and Chronic Disease Status Report of Chinese Residents (2015), ${ }^{[2]}$ and relevant media reports, ${ }^{[3]}$ the recessive obesity of Chinese women is becoming increasingly prominent. Recessive obesity, which means the body mass index (BMI) value is in the normal range, but the body fat percentage exceeds the limits, is ignored by most people. ${ }^{[4]}$ Previous studies have shown that the recessive obesity rate of adolescents has been increasing year by year, and recessive obesity is extremely difficult to detect. Further development may induce various cardiovascular and metabolic diseases such as hypertension, hyperlipidemia and fatty liver, ${ }^{[5]}$ which seriously affects their physical and mental health.

This paper defines the recessive obesity from basic level and analyzes how to prevent recessive obesity. Then we carried out experiments to demonstrate that combining exercise intervention and nutrition health education can improve health and cardio-pulmonary function of students with recessive obesity. Therefore, the results offer an effective way to control the recessive obesity of students in advance.

\section{Research objects and methods}

\subsection{Research objects}

We recruited 300 female college students from $\mathrm{H}$ University and selected 60 students from them to attend the experiment. The chosen students satisfy the judgment standard of recessive obesity $(18.5 \mathrm{~kg} / \mathrm{m} 2 \leqslant \mathrm{BMI}<24.0$ $\mathrm{kg} / \mathrm{m} 2$, and body fat percentage $>30 \%$ ), pass physical examination and come from different majors. Then these students are divided into three groups randomly: Group C 
(control group), Group E (exercise intervention group), Group $\mathrm{E}+\mathrm{H}$ (exercise intervention + nutrition health education group). The students in Group $\mathrm{C}$, as comparisons of the students in other groups, live a normal with their own habits and pace.

\subsection{Experiments}

\subsection{1 exercise intervention}

In Group E, team exercises (including aerobic exercise and resistance training, see Table 1) and individual exercises were combined to intervene students' living habits. The team exercises were arranged at 5:00-6:00 pm on Monday, Wednesday, and Friday. The maximum heart rate HRmax $=220$ - physiological age. The heart rate was monitored by using telemetry heart rate meter and counting their pulse by themselves. The experiments were implemented from September 2019 to December 2019. Professional teachers was performing medical supervision during the team exercises to ensure the safety and effectiveness of the exercise programs

Individual exercises are based on the plans that students and teachers consulted together. Students chosen the exercise programs that they are interested in, carried out the plan by themselves, and gave feedback to the teachers on a regular base. Exercise intensity was controlled by measuring their pulse immediately for $10 \mathrm{~s}$ before, during, and after each exercise.

Table1 Team exercises plan

\begin{tabular}{|c|c|c|c|c|}
\hline & Sports & $\begin{array}{l}\text { exercise } \\
\text { intensity }\end{array}$ & time & frequency \\
\hline $\begin{array}{c}\text { Preparation } \\
\text { Basic part } \\
\text { End part }\end{array}$ & $\begin{array}{l}\text { jogging, flexibility exercises; } \\
\text { aerobics, long distance running, brisk walks, climbing } \\
\text { mountains, climbing steps, running uphill, basketball, } \\
\text { volleyball, badminton, and so on; } \\
\text { resistance training (flexion and extension of shoulders, } \\
\text { elbows, knees and hips); } \\
\text { stretching exercises, relaxation exercises }\end{array}$ & $\begin{array}{c}40-60 \% \\
\text { HRmax } \\
60-80 \% \\
\text { HRmax } \\
60-80 \% \\
\text { HRmax } \\
65-70 \%(1 \mathrm{RM}) \\
30-50 \% \\
\text { HRmax }\end{array}$ & $\begin{array}{l}5 \mathrm{~min} \\
30 \mathrm{~min} \\
15 \mathrm{~min} \\
5 \mathrm{~min} \\
5 \mathrm{~min}\end{array}$ & $\begin{array}{c}\text { jogging for } 3 \text { circles, } \\
\text { stretching } \\
\text { constant practice } \\
\text { repeating the } \\
\text { exercises many } \\
\text { times } \\
3 \text { groups, } 3 \text { times for } \\
\text { each group } \\
\text { stretching, } \\
\text { relaxation }\end{array}$ \\
\hline
\end{tabular}

\subsection{2 nutrition health education}

Peer education method was employed to carry out the nutrition health education in Group $\mathrm{E}+\mathrm{H}$ for 8 weeks (10:00-11:00 am, Sunday). During the experiments, we selected 5 female college students with active mind and good communication skill and trained them with knowledge of recessive obesity. Then these five students imparted this knowledge to other students, guided them in nutrition, gave out daily dietary and activity energy consumption heat meter, recorded and analyzed dietary pattern and daily activities, and gave suggestions on how to adjust dietary pattern. The students are suggested to intake adequate dietary fiber, vegetables and fruits with low-calorie, food with high protein, low fat, low sugar to balance nutrition and reduce meditation time (the period of using mobile phones and computers) as short as possible. Besides, the students in this group are supervised by themselves and the five peers.

Table 2 The content of nutrition health education

\begin{tabular}{|c|c|}
\hline & Content \\
\hline 1st week & $\begin{array}{c}\text { What is recessive obesity, overweight and fat? Why does this happen? How } \\
\text { are they measured? }\end{array}$ \\
\hline 2nd week & $\begin{array}{l}\text { Why does recessive obesity occur? What are the hazards? Short-term } \\
\text { hazards, long-term hazards, and so on. }\end{array}$ \\
\hline 3rd week & $\begin{array}{l}\text { How to investigate life habits, how to identify their own bad habits and } \\
\text { correct?How to build good habits? }\end{array}$ \\
\hline 4th week & $\begin{array}{l}\text { The concept of "junk food" and "healthy food", how to achieve a reasonable } \\
\text { diet and nutrition? }\end{array}$ \\
\hline 5 th week & $\begin{array}{l}\text { How to investigate sleep duration and quality? How to adjust and improve } \\
\text { it? }\end{array}$ \\
\hline 6th week & $\begin{array}{c}\text { How to monitor weight and how to control it? Introducing methods to lose } \\
\text { weight? }\end{array}$ \\
\hline 7th week & $\begin{array}{l}\text { The forms and benefits of exercise, how to investigate exercise habits, how } \\
\text { to achieve scientific exercise? }\end{array}$ \\
\hline 8th week & How to prevent the recessive obesity? How to develop an exercise plan. \\
\hline
\end{tabular}




\subsection{Measurements}

Body composition indicators: Subjects were required to fast 2 hours before the test, and the body mass index (BMI), body fat percentage (BF\%), visceral fat index (VFI) and other indicators were measured by the body composition analyzer (In Body570, Korean) from 7:00 to 9:00. The waist circumference and hip circumference are measured with a plastic band ruler, and the waist-hip ratio is calculated according to the measurement data.

Physical fitness test: The health fitness indexes such as $800 \mathrm{~m}$, standing long jump, sit-up for $1 \mathrm{~min}$, sit and reach were measured using The Hengkangjiaye tester (HK6800TQ).

\subsection{Mathematical statistics and analysis}

All data were statistically processed and analyzed using

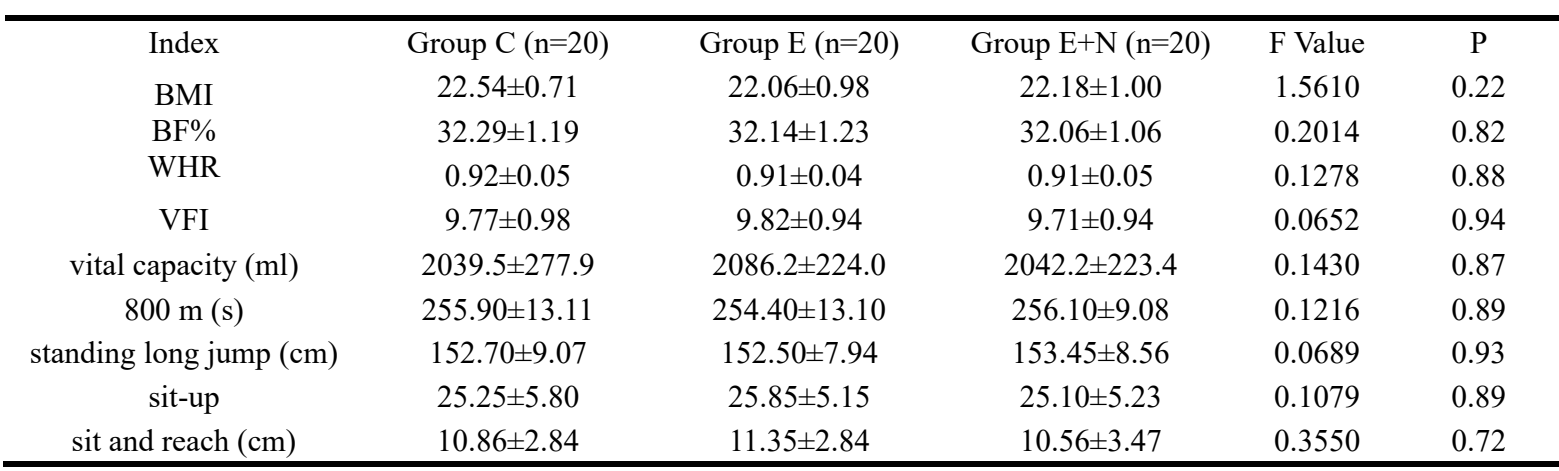

\subsection{The effect of comprehensive intervention on health fitness of female college students with recessive obesity}

\subsubsection{Comparison in the same group}

After 16w's intervention (see Table 4), students' body composition indexes, such as $\mathrm{BMI}, \mathrm{BF} \%$, and VFI,
SPSS 22.0. Mean \pm standard deviation was used to describe the measurement data. After all data were tested for normality, paired samples was used for intra-group comparison.

\section{Results}

\subsection{Screening and equalization of subjects}

The basic information of the college students with recessive obesity before the experiment were shown in Table 3. There was no significant difference between different groups, indicating that all the indexes in each group belonged to a homogeneous population before the experiment. The random grouping scheme met the requirements of the experiment, and the experimental data were reliable.

decreased significantly in Group E and Group E+N. Compared with the body composition indexes before exercise, all the indexes in Group $\mathrm{E}$ has significant differences $(\mathrm{P}<0.05)$ except WHR, while $\mathrm{BMI}, \mathrm{BF} \%$, WHR, VFI in Group E $+\mathrm{H}$ has changed significantly.

The body fitness scores of students, such as vital capacity, 800-Metre Race, standing long jump, sit-up, sit and reach, improved significantly $(\mathrm{P}<0.05)$ in Group $\mathrm{E}$ and Group E+N. Besides, Group $\mathrm{E}+\mathrm{N}$ performed more significant improvements $(\mathrm{P}<0.01)$ than Group $\mathrm{E}$.

Table 4 The body composition and physical fitness of students with recessive obesity after the experiment $(\bar{X} \pm S)$

\begin{tabular}{|c|c|c|c|c|c|c|}
\hline & Group C & $\mathrm{P}$ value & Group E & P value & Group E+N & $\mathrm{P}$ value \\
\hline BMI & $22.68 \pm 1.11$ & 0.4929 & $21.64 \pm 0.85$ & $0.0256^{*}$ & $20.28 \pm 1.52$ & $0.0002 * *$ \\
\hline $\mathrm{BF} \%$ & $32.59 \pm 1.15$ & 0.1878 & $31.69 \pm 0.88$ & $0.0133 *$ & $30.95 \pm 1.28$ & $0.0042 * *$ \\
\hline WHR & $0.91 \pm 0.04$ & 0.1487 & $0.88 \pm 0.05$ & 0.0813 & $0.88 \pm 0.6$ & $0.0405^{*}$ \\
\hline VFI & $9.67 \pm 0.89$ & 0.1706 & $9.47 \pm 0.63$ & $0.0281 *$ & $9.08 \pm 0.51$ & $0.0034 * *$ \\
\hline vital capacity (ml) & $2053.4 \pm 263.7$ & 0.8648 & $2226.7 \pm 230.3$ & $0.0112 *$ & $2287.6 \pm 326.6$ & $0.0048 * *$ \\
\hline $800 \mathrm{~m}$ & $256.80 \pm 15.61$ & 0.8135 & $243.55 \pm 14.61$ & $0.0211 *$ & $234.50 \pm 12.20$ & $0.0000 * *$ \\
\hline $\begin{array}{l}\text { standing long jump } \\
(\mathrm{cm})\end{array}$ & $153.75 \pm 5.61$ & 0.5258 & $156.95 \pm 6.19$ & $0.0127 *$ & $160.50 \pm 6.43$ & $0.0028 * *$ \\
\hline sit-up & $25.60 \pm 5.54$ & 0.7977 & $27.95 \pm 4.86$ & $0.0382 *$ & $31.20 \pm 4.93$ & $0.0006 * *$ \\
\hline sit and reach $(\mathrm{cm})$ & $11.03 \pm 2.74$ & 0.1670 & $12.13 \pm 2.44$ & $0.0346^{*}$ & $13.74 \pm 2.53$ & $0.0009 * *$ \\
\hline
\end{tabular}

$*: \mathrm{P}<0.05 ; * *: \mathrm{P}<0.01$ (compared with the indexes of experimental group before the experiment)

$\#: \mathrm{P}<0.05 ; \quad \# \#: \mathrm{P}<0.01$ (the experimental group was compared with the control group after the experiments) 


\subsubsection{Comparison among different groups}

Compared with group $\mathrm{C}$, the values of $\mathrm{BMI}, \mathrm{BF} \%$, and VFI in group $\mathrm{E}$ and Group $\mathrm{E}+\mathrm{N}$ were significantly reduced $(\mathrm{P}<0.05)$, vital capacity, 800-Metre Race, sit-up, sit and reach performances were significantly improved $(\mathrm{P}<$ 0.05). Compared with Group E, BMI, BF\%, VFI, and WHR in Group E+N reduced significantly, and there were significant differences in BMI, BF\%, and VFI $(\mathrm{P}<0.05)$. The lung capacity and standing long jump in Group E+N improved slightly, and there were significant differences in $800 \mathrm{~m}$, sit-up, sit and reach performances $(\mathrm{P}<0.05)$.
A Comparison of BMI average of the Comparative and Experimental Group

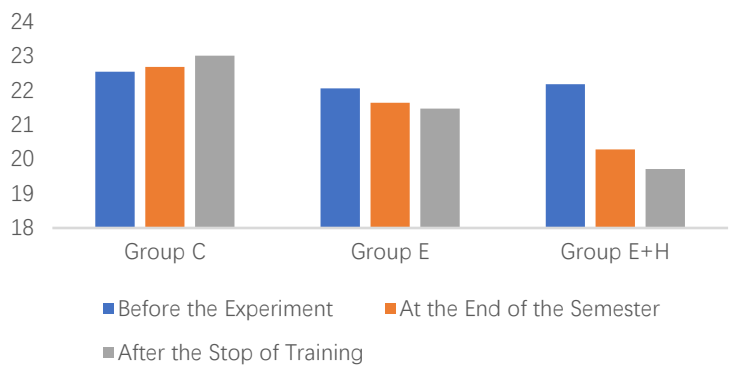

Chart 1 the Differences of BMI Average of Various Groups and Experimental Group

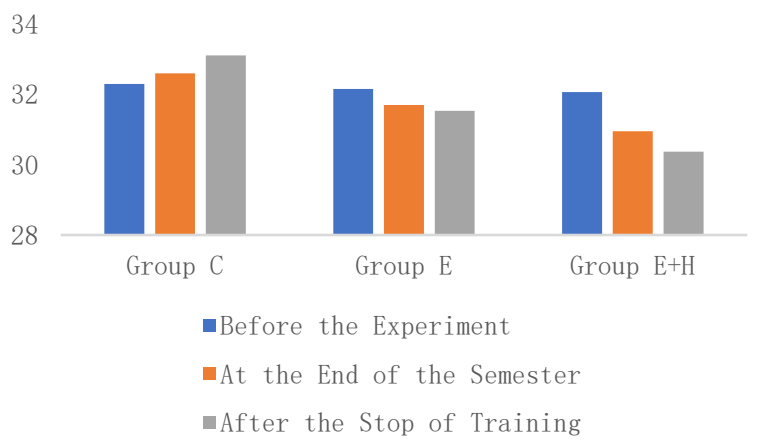

Chart3 the Differences of $\mathrm{BF} \%$ Average of Various Groups

\section{Analysis and discussion}

Zhaohui Liu et al. [6] showed that the recessive obesity rate among female college students has been increasing year by year, and the detection rate was as high as $28.6 \%$, which was relatively serious. Weight loss is the eternal theme of women. Female college students usually control their weight by skipping breakfast or excessive diet to control weight due to the lack of scientific nutrition knowledge and relevant guidance. Therefore, their weights are in standard scope, but the body fat rates exceed the limit, which is the symptom of recessive obesity.

\subsection{The change of body compositions in different groups after $8 \mathrm{w}$ exercise prescription intervention}

The body compositions were measured again after stopping exercise prescription intervention for $8 \mathrm{w}$ (Figure 1-4). Compared with the results at the end of experiment, BMI, BF\%,WHR, and VFI in Group C showed a significant upward trend, while BMI and BF\% in Group E had no significant change, WHR and VFI in Group E increased slightly. The value of $\mathrm{BMI}, \mathrm{BF} \%$, and VFI in Group $\mathrm{E}+\mathrm{N}$ decreased significantly and showed outstanding difference $(\mathrm{P}<0.05)$.

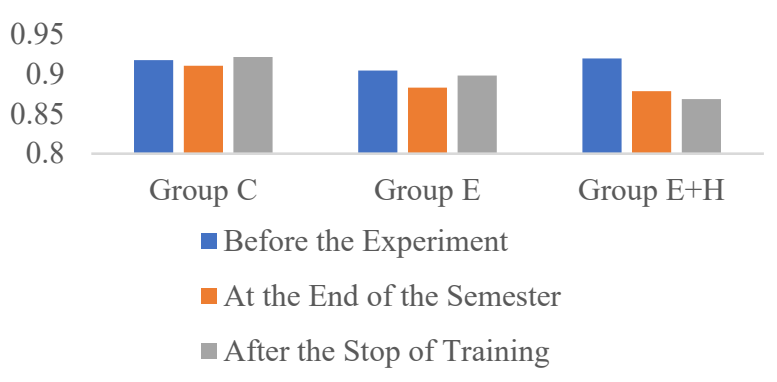

Chart2 the Differences of WHR Average of Various Groups A Comparison of VFI average of the Comparative and
Experimental Group

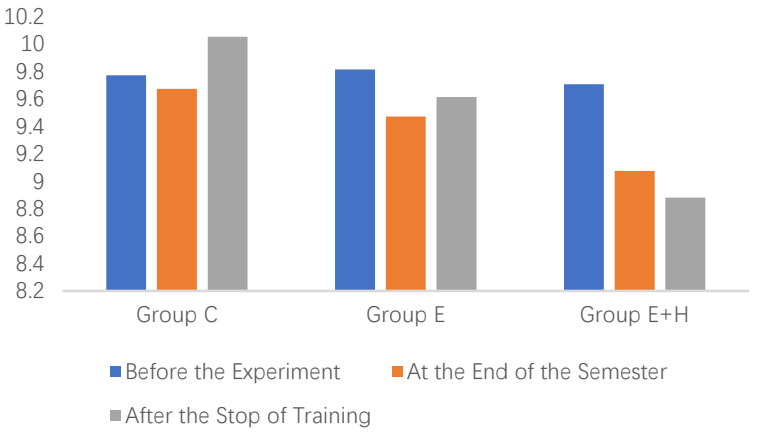

Chart4 the Differences of VFI Average of Various Groups

\subsection{The Influence of exercise and nutrition health education on body composition of female college students with recessive obesity}

The results showed that exercise prescription intervention, combining aerobic exercise with resistance exercise, could effectively reduce body composition such as BMI, BF\%, and VFI of female college students with recessive obesity, which is in line with the study of Juan Li et al. [7]. According to the theory of energy metabolism balance, bad living habitats such as lack of physical exercise and excessive nutrition are the main causes of recessive obesity. The research reports show that female college students gain about $0.4 \mathrm{~kg}$ per person during winter vacation due to prolonged sitting time, the temptation of delicious food and snacks, which is also one of the 
important reasons for the continuous weight gain. Eight weeks after the cessation of exercise intervention during the winter vacation, the $\mathrm{BMI}, \mathrm{BF} \%$ and VFI values of the students in the control group increased significantly, which may be generated from the lack of physical activities. The BMI, BF\% and VFI of students in the exercise intervention group tended to be stable, which may be due to the fact that the combination of aerobic exercise and resistance exercise could reduce the body composition, or may be related to the fact that the students developed the habit of exercise during the experiment and could still insist on it. For students in exercise intervention + nutrition health education group, their BMI, BF \%, and VFI dropped a lot. The results can be resulted from the fact that nutrition and health education changed students' behavior, enabled them to have certain health knowledge, made them have the perseverance to decline delicious food and control their body compositions through reasonable physical exercise. It is suggested that exercise and balanced nutrition can promote the physical improvement of female college students with recessive obesity. Therefore, carrying out nutrition and health education, imparting reasonable nutrition knowledge, and encouraging students to develop healthy exercise and eating habits will be the most effective and economic methods.

\subsection{Influence of exercise and nutrition health education on physical fitness of female college students with recessive obesity}

The results show that exercise intervention can significantly improve the vital capacity, 800-Metre Race scores, and sit-ups scores of female college students with recessive obesity. This variation is due to that aerobic exercises and resistance exercises can activate the respiratory muscle groups of students, increase the respiratory capacity and vital capacity. However, the scores of standing long jump and sit and reach of students improved a little, which may results from the lack of exercise that related to flexibility. In the future research, flexibility exercises are supposed to added to achieve the overall improvement of physical fitness. In addition, the exercise intervention method, combining the concentrated exercise prescription and personal contract exercise, can make students take an active part in sports exercise and obey the exercise contract according to their physical fitness condition. The feedback from teachers and self supervision are also contributed to improve their physical fitness level.

\section{Conclusions}

This study proposed a new exercise intervention method that combines exercise prescription and personal contract exercise and verified its effectiveness in decreasing the body composition and improve physical fitness level of female college students with recessive obesity. The results show that combining exercise intervention and nutrition and health education is obviously better than the single exercise intervention and can help students develop reasonable eating and exercise habits. It is suggested that attention should be paid to increase the content of lower limb explosive power and flexibility exercises in the exercise prescription study in the future, and the time of exercise intervention and nutrition and health education is supposed to be extended.

\section{Acknowledgement}

The study was supported by "Sports Science Project of Hunan Province (Grant No. 2020XH015)". The study was supported by "The Project of Ideological and Political Construction of Graduate Student Course in Central South University in 2020 (Grant No.2020YJSKSA06)".

\section{References}

1. Lu Xiaolei. Comparison of blood pressure and blood biochemical indexes between recessive obesity and normal junior high school students [J]. Chinese Journal of School Health, 2008,39(3): 429-431.

2. Fan Jinqin, Zhang Xiangqun, Fu Liming, et al. Effects of different exercise modes on body composition of recessive obese female college students $[\mathrm{J}]$. Chinese Journal of School Health,2016,37(3):354-357.

3. Liu Zhaohui, Jiao Jie, Pang Yajun, et al. Relationship between lifestyle negative emotion and obesity degree of female college students in Henan Province[J]. Chinese Journal of School Health, 2020,41(2):239-242.

4. Li Juan, Tang Donghui, Chen Wei. Improvement and possible mechanism of aerobic exercise combined with resistance training on cardiovascular function in obese male adolescents[J]. China Sport Science, 2013,33(8):37-42. 